\title{
Study on community structure of microbial consortium for the degradation of viscose fiber wastewater
}

\author{
Chao-Qun Ding ${ }^{1}$, Kun-Rong Li ${ }^{1}$, Yun-Xia Duan², Shi-Ru Jia ${ }^{1}, \mathrm{He}-\mathrm{Xin} \mathrm{Lv}^{1}, \mathrm{He} \mathrm{Bai}^{3}$ and Cheng Zhong ${ }^{1 *}$
}

\begin{abstract}
Background: Enrichment culture was applied to obtain microbial consortium from activated sludge samples collected from biodegradation system, a chemical fiber plant in Hebei Province, China. Bacterial composition and community dynamic variation were assessed employing denaturing gradient gel electrophoresis fingerprinting technology based on amplified 16S rRNA genes in the entire process of enrichment culture for viscose fiber wastewater.
\end{abstract}

Results: Four bacteria named as VF01, VF02, VF03, and VF04 were isolated from the microbial consortium adopting the spray-plate method. The DNA bands of these four bacteria were corresponded to the predominant DNA bands in the electrophoresis pattern. VF01, VF02, VF03, and VF04 were phylogenetically closed to Bacillus licheniformis, Bacillus subtilis, Paracoccus tibetensis, and Pseudomonas sp. by sequence analysis, respectively. The degradation effects for $\mathrm{COD}_{\mathrm{Cr}}$ of single isolated strain, mixed strains, and microbial consortium (VF) originally screened from viscose fiber wastewater were determined. The degradation ability was as follows: microbial consortium (VF) > mixed strains $>$ single isolated strain. Microbial consortium (VF) showed the optimum degradation rate of $\mathrm{COD}_{\mathrm{Cr}}$ of $87 \%$ on 14 th day. Degradation of pollutants sped up by bio-augmentation of four strains. The molecular weight distribution of organic matter showed that viscose fiber wastewater contained a certain amount of large molecular organic matter, which could be decomposed into smaller molecular substances by microbial consortium (VF).

Conclusions: The microbial consortium (VF) obtained from enrichment culture exhibited great potential for $C O D_{\mathrm{Cr}}$ degradation. The screened strains had bio-augmentation functions and the addition of a mixture of four bacteria could speed up the degradation rate of pollutants.

Keywords: Viscose fiber wastewater, Bio-augmentation technology, Community structure, DGGE fingerprinting technology

\section{Background}

Viscose fiber exhibits good physical, mechanical, and servicing qualities, and its status is next to polyester in chemical fiber industry (Lin 2000). Nowadays, a huge volume of wastewater has been produced in chemical industry which is responsible for serious environmental problems. Viscose fiber wastewater contains acid and alkaline wastewater. Acid wastewater is characterized

\footnotetext{
*Correspondence: czhong@tust.edu.cn

${ }^{1}$ Key Laboratory of Industrial Fermentation Microbiology, (Ministry of Education), Tianjin University of Science \& Technology, Tianjin 300457, People's Republic of China

Full list of author information is available at the end of the article
}

by foul-smelling, high zinc ion concentration, high temperature, high salinity, sulfide, complex composition, and toxic substances. Alkaline wastewater is characterized by caustic soda and cellulose with low polymerization degree (Liang et al. 2009; Wang et al. 2013). The contaminants, as cellulose and lignin, in the wastewater are hard to be biodegraded and cause serious environment pollution, therefore it is very difficult to effectively deal with industrial wastewater (Kang and Yi 2005). These are the main reasons why the viscose fiber production has been kept stagnated over the past 20 years. Thus, it is of great social and environmental benefits to develop wastewater treatment technology. 
The mixed wastewater of viscose fiber is mainly used in the industrial degradation. A large number of cellulose precipitate was formed after acid and alkaline wastewater were mixed $(\mathrm{pH}=2-3)$ in the industrial degradation. At the same time, sulfide is turned into hydrogen sulfide and carbon disulfide in recycling (Liang et al. 2009). Zinc ions are turned into zinc hydroxide precipitation when the $\mathrm{pH}$ value was $8-9$. Several physical and chemical methods have been used to treat wastewater and improve the degradation efficiency of $\mathrm{COD}_{\mathrm{Cr}}$ (Hamaguchi et al. 2013; Kang et al. 2012). However, the cost is too high and the equipment covers a large area. In contrast, biological processes are the most environmental friendly and economical (Miao et al. 2009). However, no microorganism has been reported that can directly degrade viscose fiber wastewater, due to the complex composition of viscose fiber wastewater, most of which are cellulose, lignin, organic pollutants, and other large molecular substances (Liang et al. 2009; Vikman et al. 2002). It has been observed that few microorganisms can degrade macromolecular substance under high salinity condition (Kanaly and Harayama 2000).

Previous studies indicated that small molecular substances could be degraded by individual strain or single species (Kanaly and Harayama 2000; Head and Oleszkiewicz 2004). In contrast, large molecular substances should be degraded by diverse species of microorganisms, because the degradation could not be completed by individual type and the cooperation of diverse species is necessary (Kanaly et al. 2000). To study the degradation of viscose fiber wastewater by microorganisms, organic matter is converted through a range of metabolic reactions by assembling of microorganisms in wastewater environment.

It is possible to describe bacterial diversity in real environment by combining molecular biology technology based on 16S rRNA gene analysis and culture-dependent approaches as there have been a number of advances in microbial ecology. PCR-DGGE is a useful and powerful tool for describing the structure changes of microbial community in complex wastewater environments and enrichment cultures. PCR-DGGE has been widely used to identify the bacterial composition of different ecological niches, as these approaches are able to detect microorganisms which are not detected by culture-based methods (Muyzer and Smalla 1998; Brito et al. 2006). Molecular biology technology has contributed to further conduct the studies involving microbial composition, phylogeny, and metabolic mechanism during the whole wastewater treatment process (Al-Thukair et al. 2007; Widada et al. 2002).

The purpose of this paper was to (1) apply the viscose fiber wastewater enrichment strategy to establish viscose fiber wastewater degrading communities to enhance biodegradation of viscose fiber wastewater; (2) analyze the structure changes of bacterial community in viscose fiber wastewater by PCR-DGGE; (3) detect the biodegradability of bacterial consortium gathered from viscose fiber wastewater.

\section{Results and discussion \\ DGGE analysis of community structure}

Ten bands were observed during enrichment process, indicating that the dynamic variation of bacterial community was complex. Figure 1 shows that the intensity of bands 2 and 6 were relatively high in the first lane (the first enrichment), while bands 2 and 6 were not found in the same position of other lanes. These results indicated that these two strains showed low degradation activities to contaminants in viscose fiber wastewater and were unaccommodated to high pressure. While the other strains showed high degradation activities to contaminants in viscose fiber wastewater and were accommodated to high pressure. During enrichment culture, bands 1 and 10 gradually turned bright, demonstrating that these two strains were the predominant microorganisms and showed strong abilities in degradation. Bands 3 ,

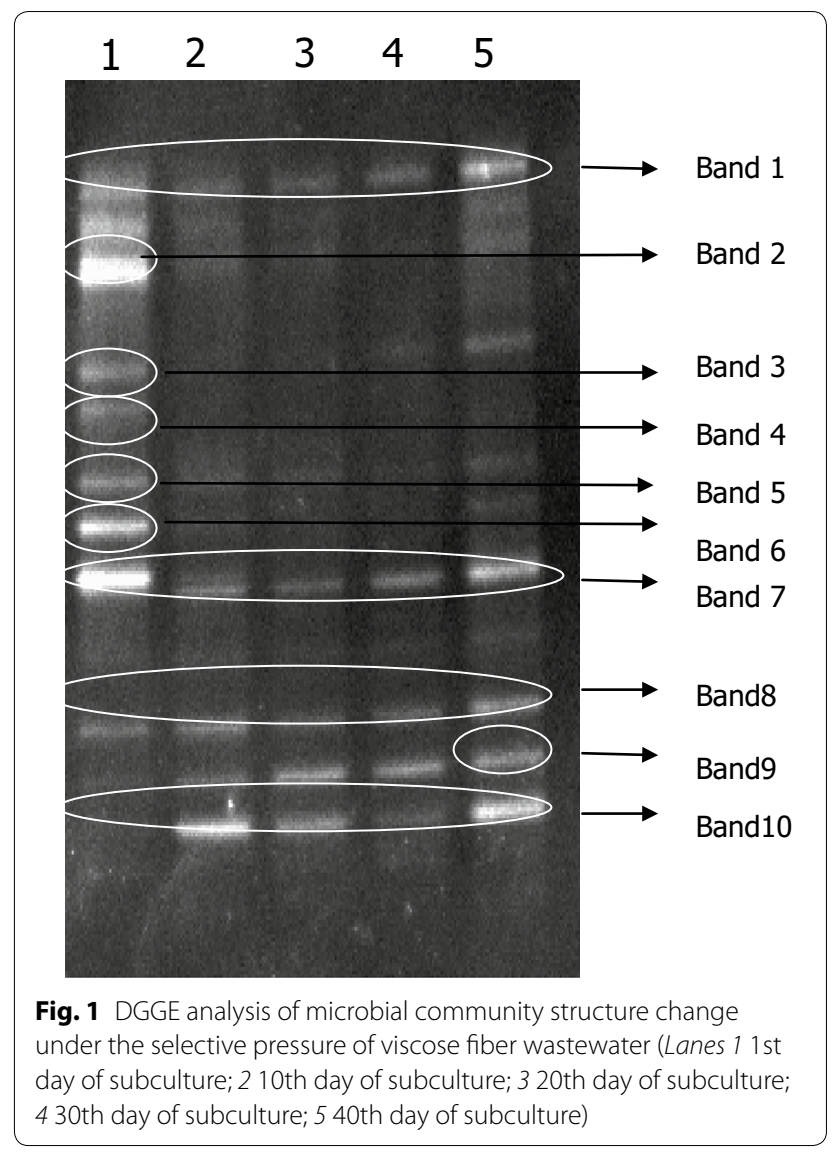


4 , and 7 gradually turned dark and band 4 even could not be found in the later enrichment culture, demonstrating that the number of population tended to reduce during enrichment culture; however, some strains were still predominant for degradation. Bands 8 and 9 remained to be bright in all lanes during enrichment culture, suggesting that these strains might utilize organic matter in wastewater as $\mathrm{C} / \mathrm{N}$ source.

\section{DGGE analysis of mixed culture}

Four strains, VF01, VF02, VF03, and VF04, were isolated from the 5th enrichment culture. Bands in VF01, VF02, VF03, and VF04 were well correlated with the corresponding bands of the mixed culture in the PCRDGGE (Fig. 2). In theory, DNA fragments corresponding to bands on the same horizontal line have identical sequence, the electrophoretic mobility of band 7 was identical with strain VF01; band 8 with strain VF02; band 9 with strain VF03; band 10 with strain VF04. These four bands existed in the whole enrichment cultures, confirming that these four isolate strains exhibited advantage in removing contaminants from wastewater compared with other isolated strains.

\section{Phylogenetic analysis}

Bands 1, 2, 7, VF 01, VF 02, VF 03, and VF 04 were excised from gels following by identification of strains and analysis of phylogeny based on the 16S rRNA sequence (Figs. 1, 2). Bands 1, 2, and 7 were identified to be Pseudomonas sp. (191 bp, 99\% identical), Pseudomonas sp. (201 bp, 99\% identical), and Bacillus sp.

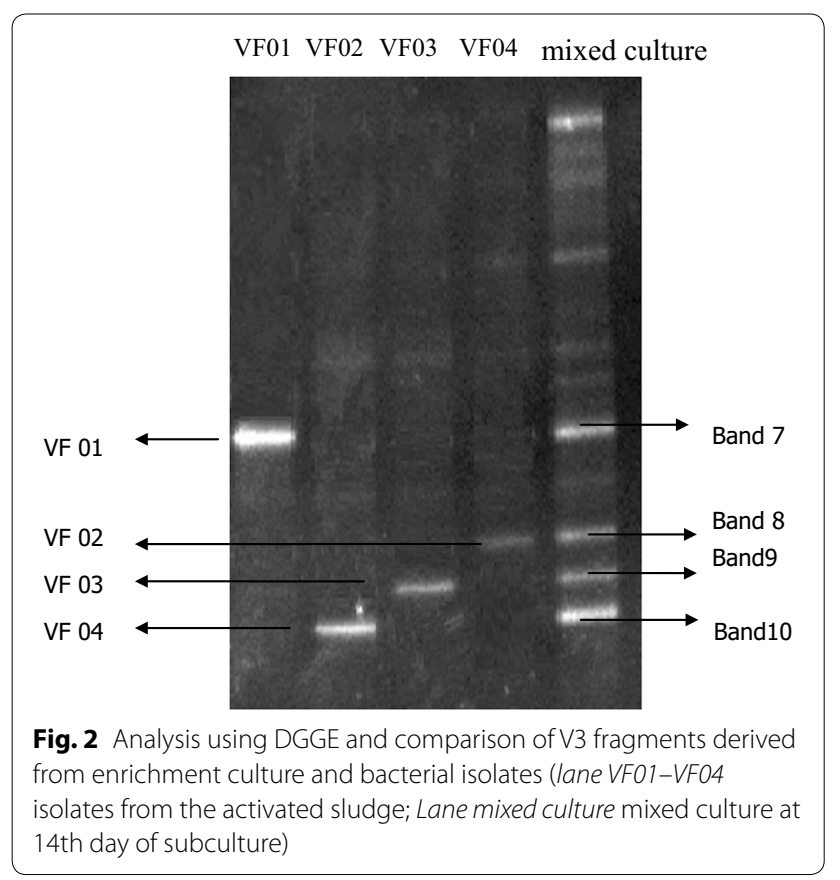

(203 bp, 100\% identical), respectively. Bands VF 01, VF 02, VF 03, and VF 04 were identified to be Bacillus licheniformis (1451 bp, 100\% identical), Bacillus subtilis (1437 bp, 100\% identical), Paracoccus tibetensis (1378 bp, 98\% identical), and Pseudomonas sp. (1459 bp, 100\% identical), respectively.

Phylogenetic tree for these strains was developed (Fig. 3). VF01 and VF02 belonged to Bacillus sp., which was the common microorganism used for biodegradation and purification of industrial wastewater (e.g., Bacillus pumilus). Bacillus sp. had apparent advantage in degrading organic pollutants, such as organic phosphorus pesticides, petroleum pollutants, polycyclic aromatic hydrocarbons, phenol, and nitrobenzene (Devaraja et al. 2002; Oliveira et al. 2009; Gopinath et al. 2009; Singh et al. 2008; Wen et al. 2011). Bacillus sp. are widely distributed in the natural environment, some of which can grow well under high acid, high alkali, high temperature, and cold condition, making it possible to decompose complex polysaccharide, protein, and soluble organics.

VF03 was $98 \%$ identical with $P$. tibetensis sp., which is a kind of denitrification bacteria and can be separated from the wastewater plant. P. tibetensis sp. is mainly used in sewage treatment, such as landscape water treatment, urban river governance, especially aquaculture wastewater treatment.

VF04 was 99\% identical with the Pseudomonas sp., which is widely distributed in the nature and has the ability to metabolize a series of compounds, such as polycyclic aromatic hydrocarbons, toluene, cyanide, carbazole, simple aromatic compounds, organic solvent in organic compounds, and chlorinated hydrocarbons (Reineke 1998).

\section{Degradation rate of $\mathrm{COD}_{\mathrm{cr}}$}

The degradation rate of $\mathrm{COD}_{\mathrm{Cr}}$ of individual strains, mixed strains, and the enriched consortium (VF) were measured to better understand the metabolic capabilities of consortium. As shown in Fig. 4, after incubated for 14 days, strain VF01 could degrade $10 \%$ of $\mathrm{COD}_{\mathrm{Cr}}$; strain VF02 could degrade $7.5 \%$ of $\mathrm{COD}_{\mathrm{Cr}}$; and strain VF04 could degrade $14.8 \%$ of $\mathrm{COD}_{\mathrm{Cr}}$; however, strain VF03 could not degrade $\mathrm{COD}_{\mathrm{Cr}}$ in wastewater. The degradation effect of single strain was the worst, which ranged from 0.5 to $14.8 \%$, as the viscose fiber wastewater contained complex macromolecular organic matter, such as cellulose, hemicellulose, and lignin. The degradation process involves in complex biochemical metabolic reaction and requires the synergistic action of different types of microorganisms. Bacillus sp. and Pseudomonas sp. could produce degradation enzymes of lignin and cellulose, making it possible to decompose cellulose, hemicellulose, and lignin in viscose fiber wastewater (Hernández et al. 
a

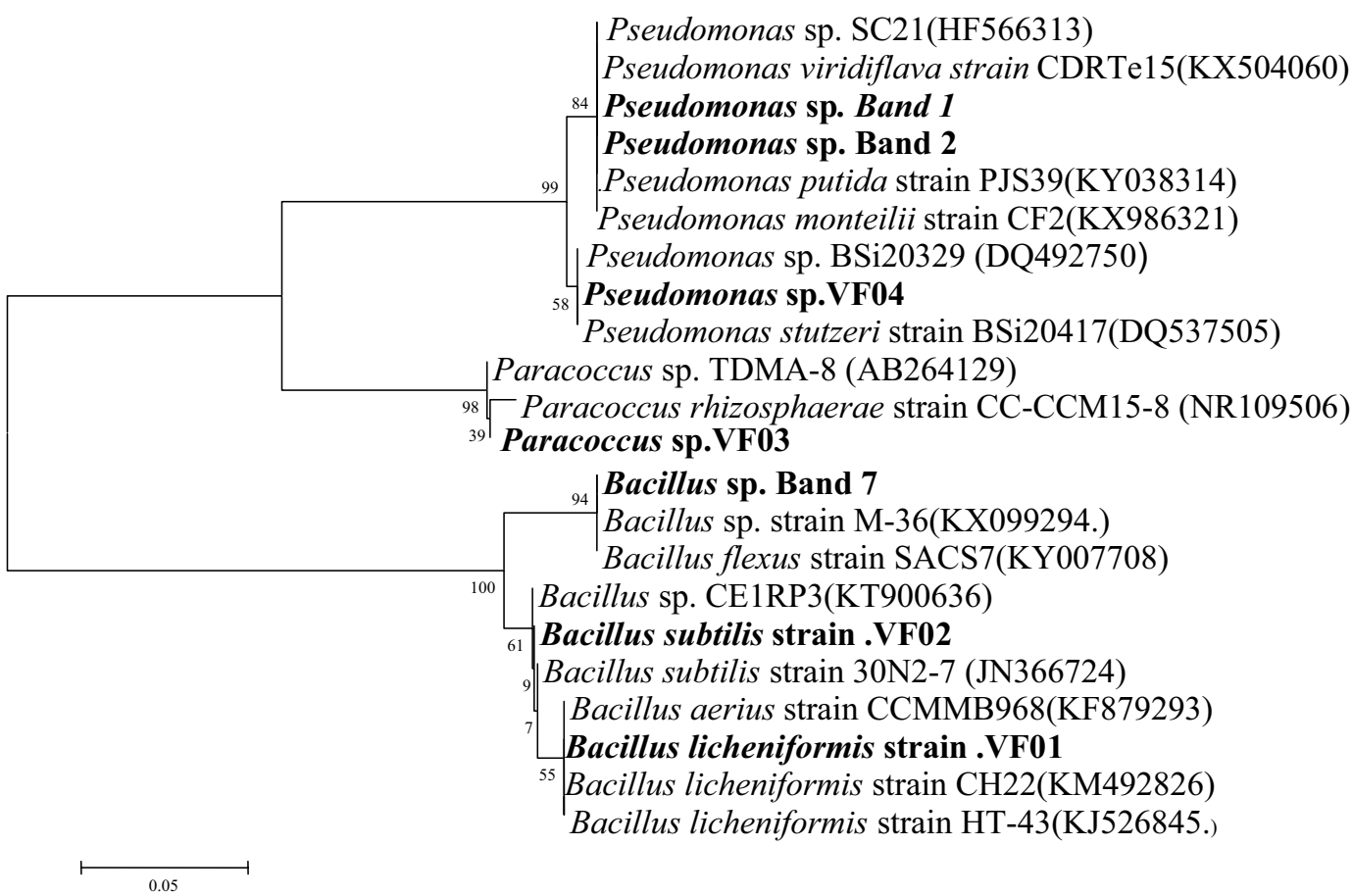

b

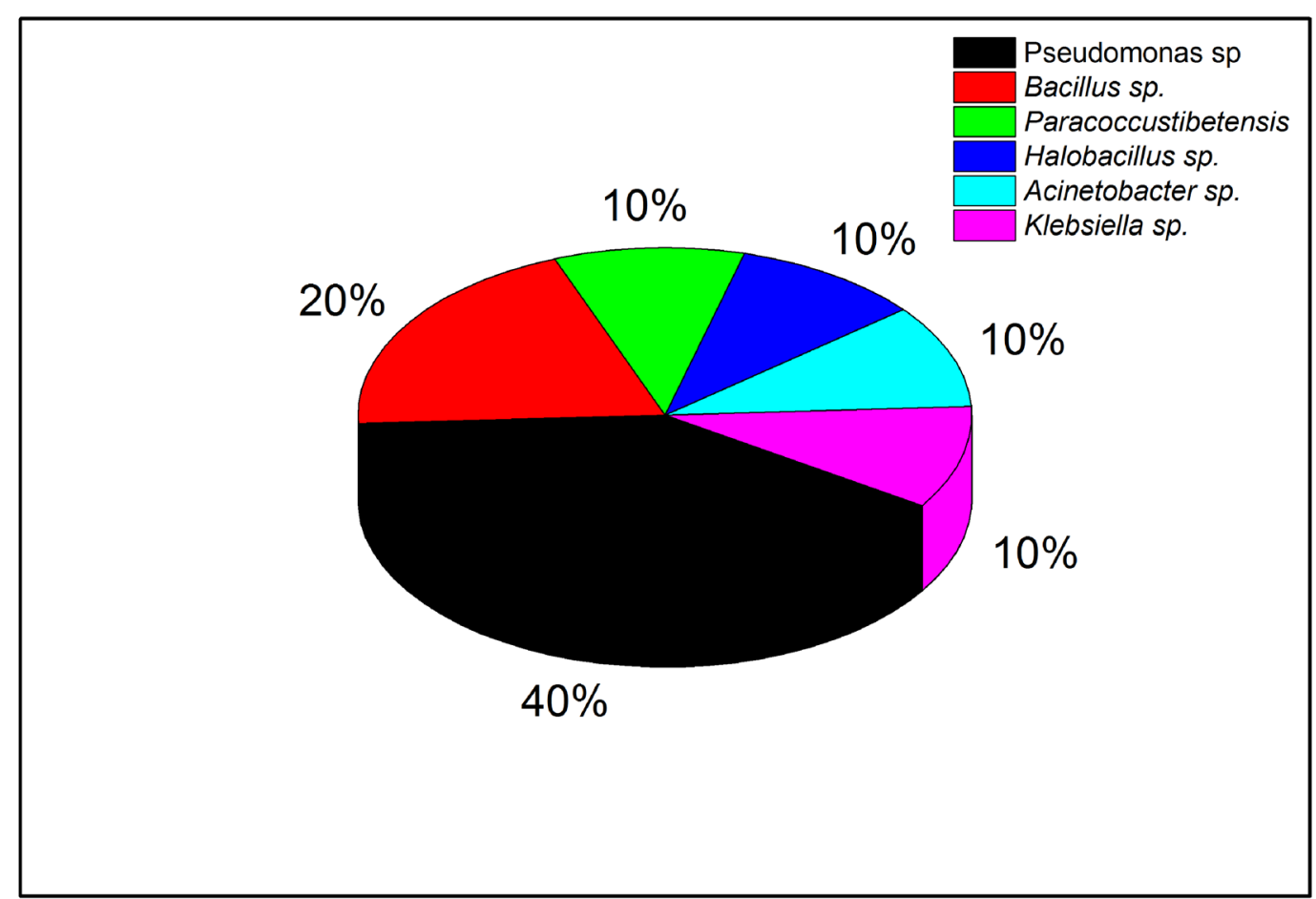

Fig. 3 a Phylogenetic tree with cut bands: Band 1, Band 2, Band 7, Band 10; isolated strains: VF01, VF02, VF03, VF04; and their closest relatives derived from GenBank data based on 16S rRNA gene analysis. b The percentage of "community" in this kind of wastewater 


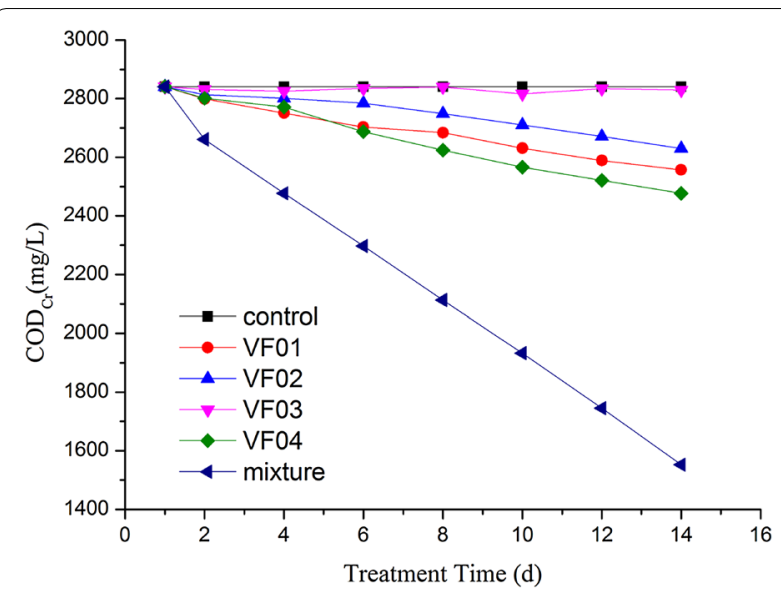

Fig. 4 Biodegradation of $\mathrm{COD}_{\mathrm{Cr}}$ by individual isolates, mixture of the four isolates, and the consortium VF

2001; Tuomela et al. 2000; Kumar et al. 2001). However, the decomposition rate is very slow because the degradation enzymes are intracellular enzyme (Schwarz 2001). P. tibetensis sp. is a kind of denitrification bacteria, which cannot produce degradation enzymes but was able to convert nitrate to nitrogen and provided the nitrogen source for the growth of other organisms.

Bacillus sp. can cooperate with Pseudomonas sp. to degrade the large molecules substances in viscose fiber wastewater, such as cellulose and lignin, etc. (Tuomela et al. 2000; Kumar et al. 2001). The mechanism of synergistic degradation has been clear now (Wilson 2004). The interaction of fungi, bacteria, and the microbial community contributed to the complete degradation of large molecules (Hernández et al. 2001), but the degradation of single Bacillus sp. or single Pseudomonas sp. on cellulose, lignin, and other large molecules was limited.

The degradation rate of $\mathrm{COD}_{\mathrm{Cr}}$ of the mixed strains, the enriched consortium (VF), and the mixture with consortium (VF) were measured to better understand the metabolic capability of the mixed strains. The degradation effect of $\mathrm{COD}_{\mathrm{Cr}}$ depicted in Fig. 5 was as follows: consortium $(\mathrm{VF})>$ the mixture of four isolates $>$ individual isolates. This is due to the number and types of microorganisms in the consortium (VF) which are more than that of mixed and individual strains. The small molecular substances can be metabolized by individual strains, while the biodegradation of macromolecular substances requires the combined efforts of different strains, especially cellulose and lignin.

After operation for 14 days, the mixed strains degraded $45.4 \%$ of $\mathrm{COD}_{\mathrm{Cr}}$, which was far below than $87 \%$ removal efficiency of consortium (VF), due to that the number and types of microorganisms in the consortium (VF) are

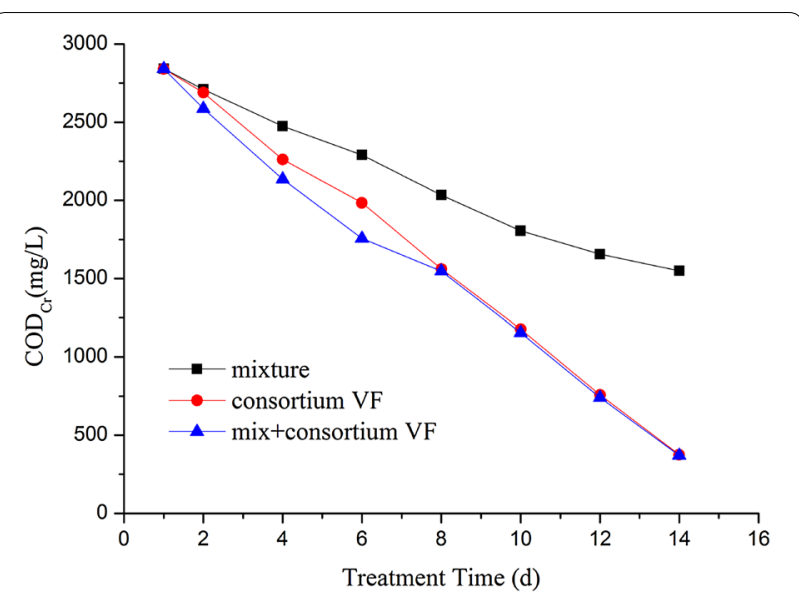

Fig. 5 Biodegradation of $\mathrm{COD}_{\mathrm{Cr}}$ by mixture of the four isolates, the consortium VF, and mixture + the consortium VF

more than that of mixture. In contrast, the degradation rate of the mixture and consortium (VF) is faster than that of consortium (VF) from the 1st to 8th day. After 8th day, the degradation rate of the mixture and the consortium (VF) was same with that of consortium (VF), indicating that partial large molecules could be degraded into small molecules by the mixture, such as cellulose and lignin, etc. The addition of the mixture in the consortium (VF) can improve the degradation effect on pollutants. Bacillus sp. and Pseudomonas sp. had bio-augmentation function and could enhance the degradation effect of viscose wastewater.

\section{Dissolved organic matters (DOM) size distribution in viscose fiber wastewater}

The molecular weight distribution of organic matter during the degradation process was measured to further analyze the bio-augmentation effect of four strains. As shown in Fig. 6, the molecular weight distribution in 10 samples was asymmetric and DOM was mainly composed of small molecules, e.g., $<1 \mathrm{kDa}$. In control sample, the percentage of DOM $(<1 \mathrm{kDa})$ reached $66.1 \%$ and the percentage of DOM $(10-3 \mathrm{kDa})$ reached $20.6 \%$. For large molecular organic matter, the percentage of DOM (>100 kDa, $100-30 \mathrm{kDa}$, and $30-10 \mathrm{kDa}$ ) reached $3.6,4$, and $5.2 \%$, respectively. Viscose fiber wastewater also contained a lot of insoluble large molecular organics, thus leading to the difficulty of further degradation. The molecular weight distribution of VF01, VF02, VF03, and VF04 was similar to that of the control group. This result was consistent with the degradation effect of $\mathrm{COD}_{\mathrm{Cr}}$ (Fig. 4).

Microbial degradation rate sped up by bio-augmentation of four strains by comparing the distribution of 


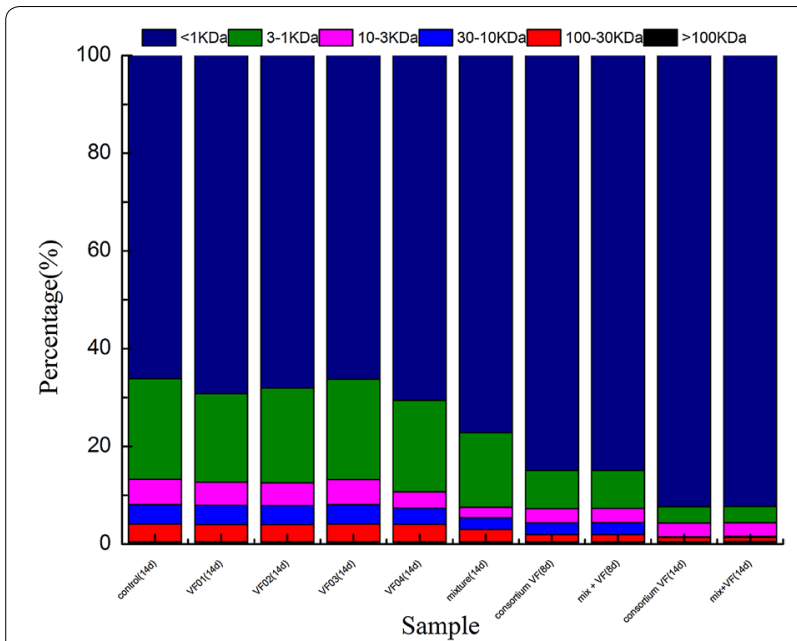

Fig. 6 The molecular weight distribution and proportion of DOM in sewage biodegraded by different combinations of microorganisms for different days [mix $+V F$ mixture with the consortium (VF)] molecular weight. The organic compounds in wastewater were accelerated into small molecules by bio-augmentation of four strains. The proportion of the large molecular organic matter in wastewater became less and less, e.g., the percentage of $100-30 \mathrm{kDa}$ changed from 3.6 to $0.85 \%$ and the percentage of $30-10 \mathrm{kDa}$ changed from 4 to $0.25 \%$. However, the fraction of small molecule organic matter became more and more, e.g., the percentage of $<1 \mathrm{kDa}$ changed from 66.1 to $92.27 \%$. The molecular weight distribution of DOM in sewage not only reflected the characteristics of organic matter but also closely related to the degradation efficiency for wastewater (Chang et al. 2000).

Bio-augmentation utilizes microorganisms as biodegraders to purify sewage in nature and bioreactors to remove contaminants (Chong et al. 1997; El Fantroussi and Agathos 2005; Head and Oleszkiewicz 2004; Reberto et al. 2003). Bio-augmentation is efficient in degrading target pollutants and removing the refractory organics involved in wastewater by inoculating strains. Previous studies indicated that bio-augmentation was feasible for the treatment of waste streams produced from pharmaceutical factories, coke plants, pulp mills, dye, and other industries (Saravanane et al. 2001; Park et al. 2008; Wang et al. 2002; Yu and Mohn 2001; Chen et al. 2006).

\section{Conclusions}

The microbial consortium for wastewater degradation was enriched from samples of viscose fiber wastewater collected from a chemical fiber plant in Hebei, China. The method of PCR-DGGE was employed to investigate the changes in microbial community structure and helped us to determine the predominant species for $\mathrm{COD}_{\mathrm{Cr}}$ biodegradation throughout the enrichment process. Consortium (VF) exhibited great potential in $\mathrm{COD}_{\mathrm{Cr}}$ removal and the degradation rate of $\mathrm{COD}_{\mathrm{Cr}}$ reached $87 \%$ until 14th day, indicating that enrichment culture as an isolation method was both feasible and effective. Four strains had biological reinforcement functions and the addition of a mixture of four bacteria could speed up the degradation rate of pollutants and the application of these species to bio-augmentation fields would assist in observing their catabolic behavior in highly polluted environments.

\section{Methods \\ Media}

Enrichment and cultivation were carried out in modified LB medium (Tryptone $5 \mathrm{~g} / \mathrm{L}$, yeast extract $1 \mathrm{~g} / \mathrm{L}, \mathrm{NaCl}$ $3 \mathrm{~g} / \mathrm{L}$, agar $1.5 \mathrm{~g} / \mathrm{L}, \mathrm{pH}$ 7.2-7.4).

\section{Sampling, enrichment, and isolation of the viscose fiber wastewater degraders}

The mixed wastewater of viscose fiber samples were collected from a chemical fiber wastewater plant in Hebei, China. Activated sludge samples were collected from biochemical treatment system. The samples were stored at $4{ }^{\circ} \mathrm{C}$ until use. The characteristics of wastewater were listed in Table 1.

Activated sludge samples $(2.0 \mathrm{~g})$ were cultured in $250 \mathrm{~mL}$ Tri-flask with $100 \mathrm{~mL} \mathrm{LB}$ media at $30{ }^{\circ} \mathrm{C}$ and $150 \mathrm{rpm}$ for 2 days. Hereafter, this culture of $10 \mathrm{~mL}$ was shifted to another flask of $250 \mathrm{~mL}$. The amount of viscose fiber wastewater was gradually increased until all wastewater was used as a microbial growth substrate at

Table 1 The characteristics of viscose wastewater sample

\begin{tabular}{ll}
\hline Parameters & Value \\
\hline $\mathrm{COD}_{\mathrm{Cr}}$ & $2800-3000$ \\
$\mathrm{BOD}_{5}$ & $860-920$ \\
$\mathrm{SS}$ & $1000-1200$ \\
$\mathrm{TN}$ & $150-200$ \\
$\mathrm{TP}$ & $75-85$ \\
$\mathrm{TDS}$ & $24-30$ \\
$\mathrm{pH}$ & $6-8$ \\
Zinc ion & $300-500$
\end{tabular}

The units for the parameters except for $\mathrm{pH}$ and salt are in $\mathrm{mg} / \mathrm{L}$, TDS is $\mathrm{g} / \mathrm{L}$ $N D$ no detectable, $C O D_{C r}$ chemical oxygen demand, $B O D_{5}$ biochemical oxygen demand after 5 day, $S S$ suspended solids, $T N$ total nitrogen, $T P$ total phosphorus, TDS salt 
10 days. The acclimation time for enrichment culture lasted for 40 days.

Bacteria were screened from the consortium by tenfold series dilution method. Morphologically distinct individual colonies were further purified on LB agar plates.

\section{DNA samples preparation}

DNA was respectively extracted from the isolated strains and the enrichment cultures, i.e., the first day of enrichment culture sample, the 10th day of enrichment culture sample, the 20th day of enrichment culture sample, the 30th day of enrichment culture sample, the 40th day of enrichment culture sample following the manufacturer's protocol (Qiagen, Valencia, CA, USA). The integrity of DNA was detected by agarose gel electrophoresis.

\section{Amplification of DNA and DGGE analysis}

The variable region V3 of the $16 \mathrm{~S}$ rRNA gene was amplified employing primers 341F (5'-CCT ACG GGA GGC AGC AG-3') with a 40-bp GC clamp at $5^{\prime}$ end (CGC CCG CGC GCG CGG CGG GCG GGG CGG GGG CAC GGG GGG) and 518R (5'-ATT ACC GCG GCT GCT GG-3') (Watanabe et al. 2001).

Cycling conditions for $16 \mathrm{~S}$ rRNA gene amplification were as follows: initial denaturation at $94{ }^{\circ} \mathrm{C}$ for $5 \mathrm{~min}$, 30 cycles each involved denaturation at $94^{\circ} \mathrm{C}$ for $1 \mathrm{~min}$; anneal at $55{ }^{\circ} \mathrm{C}$ for $1 \mathrm{~min}$, extended at $72{ }^{\circ} \mathrm{C}$ for $1 \mathrm{~min}$; and another extension at $72{ }^{\circ} \mathrm{C}$ for $10 \mathrm{~min} .5 \mu \mathrm{L}$ of PCR products was analyzed by electrophoresis on $2 \%$ agarose gel in $1 \times$ TAE buffer $(20 \mathrm{mM}$ Tris $-\mathrm{HCl}, 10 \mathrm{mM}$ glacial acetic acid, $0.5 \mathrm{mM}$ EDTA, pH 8.0) at $120 \mathrm{~V}$ for $30 \mathrm{~min}$.

Samples of PCR products were loaded onto $8 \%(\mathrm{w} / \mathrm{v})$ polyacrylamide gel within $30-60 \%$ denaturing gradient (100\% denaturant consisted of $7 \mathrm{M}$ urea and $40 \%$ deionized formamide). The electrophoresis was run in $1 \times$ TAE buffer for $10 \mathrm{~h},\left(100 \mathrm{~V}, 60^{\circ} \mathrm{C}\right)$ in Universal Mutation Detection System apparatus (Bio-Rad, Dcode, USA). Finally, the gels were stained with ethidium bromide solution of $0.1 \%(\mathrm{v} / \mathrm{v})(1 \times \mathrm{TAE})$ for $15 \mathrm{~min}$, rinsed in distilled water for $20 \mathrm{~min}$, and then were scanned in a Gel Doc XR documentation system (Bio-Rad).

\section{Identification of strains and analysis of phylogeny}

Pieces of DGGE bands were excised from polyacrylamide gel with sharp blade and then were, respectively, transferred to a new $2.0 \mathrm{~mL}$ Eppendorf tubes with $50 \mu \mathrm{L}$ of sterilized ultra-pure water and incubated at $4{ }^{\circ} \mathrm{C}$ for a night to accelerate the diffusion of DNA out of the gel bands. The centrifugation was conducted at $10,000 \mathrm{~g}$ for 6 min to obtain supernatant from above DNA solution. $1 \mu \mathrm{L}$ supernatant was used as amplified template with a set of primer $341 \mathrm{~F}$ and $518 \mathrm{R}$ with no GC clamp. Amplified products were further analyzed by the technique of denaturing gradient gel electrophoresis to confirm that they were successfully isolated.

Bacterial 16S rRNA genes were amplified employing primers $27 \mathrm{~F}\left(5^{\prime} \mathrm{V}\right.$-AGA GTT TGA TCC TGGCTC AG-3') and 1492R (5'-GGC TACCTT GTT ACG ACT T-3') (Ikenaga et al. 2002). The amplification procedure was as follows: preliminary at $94{ }^{\circ} \mathrm{C}$ for $4 \mathrm{~min} ; 30$ cycles of $94{ }^{\circ} \mathrm{C}$ for $1 \mathrm{~min}, 55^{\circ} \mathrm{C}$ for $1 \mathrm{~min}, 72^{\circ} \mathrm{C}$ for $2 \mathrm{~min}$, and a final extension at $72{ }^{\circ} \mathrm{C}$ for $10 \mathrm{~min}$.

The amplified products were purified from agarose gel and bound with a pMD18-T vector and then transformed into Escherichia coli DH5 and the recombinant clones with a $1.5 \mathrm{~kb}$ insert were sent to be sequenced by sequencing company. All generated sequences were compared with nucleotide sequences of known sequences listed in GenBank databases (http://www.ncbi.nlm.nih. gov/) using BLAST (Basic Local Alignment Search Tool). The phylogenetic tree was constructed according to maximum-likelihood analysis implemented in MEGA6 software.

\section{Biodegradation of contaminants}

Enrichment culture processes were monitored periodically to isolate the strains capable of removing $\mathrm{COD}_{\mathrm{Cr}}$ in viscose fiber wastewater. Isolated strains presenting clear colonial morphology on LB agar culture medium were further purified and incubated in LB culture media of $200 \mathrm{~mL}$ at $30^{\circ} \mathrm{C}$. The cells were harvested by centrifugation at 12,000 rpm for $10 \mathrm{~min}$ when the optical density $(600 \mathrm{~nm})$ reached at 0.6 , pellets were washed with sterile $0.85 \% \mathrm{NaCl}(\mathrm{w} / \mathrm{v})$ twice and then inoculated into conical flasks containing $300 \mathrm{~mL}$ of viscose fiber wastewater and placing on a rotary shaker $(180 \mathrm{rpm})$ at $30{ }^{\circ} \mathrm{C}$. The mixture of isolates, the consortium labeled VF, and the mixture with the consortium were added into viscose fiber wastewater under the same conditions. The culture flask containing $300 \mathrm{~mL}$ of wastewater without bacterial consortium (VF) was as control experiment. Flasks of the isolates, mixture, the consortium, and the control were taken out from the rotary shaker on the 0th, 2nd, 4th, 6th, 8th, 10th, 12th, and 14th days. The analysis of $\mathrm{COD}_{\mathrm{Cr}}$ content in each sample was carried out with Microwave digestion COD analyzer (DRB-200).

The degradation rate of $\mathrm{COD}_{\mathrm{Cr}}$ was calculated using the formula as follows:

The degradation rate $=\left(1-C_{\mathrm{e}} / C_{\mathrm{i}}\right) * 100$,

where $C_{\mathrm{i}}$ and $C_{\mathrm{e}}$ are raw water and the sample concentrations in $\mathrm{mg} \mathrm{L}^{-1}$. 
Table 2 The corresponding molecular weight cut-off range of each fraction

\begin{tabular}{ll}
\hline Fraction & Molecular weight range \\
\hline UF YM-100 & Fraction $100,000-500,000$ \\
UF YM-30 & Fraction $30,000-100,000$ \\
UF YM-10 & Fraction $10,000-30,000$ \\
UF YM-3 & Fraction $3000-10,000$ \\
UF YM-1 & Fraction $1000-3000$ \\
\hline
\end{tabular}

\section{The isolation of dissolved organic matters (DOM)}

The relative molecular weight was determined by ultrafiltration membrane method to reflect the changes of dissolved organic matter (DOM) during the biodegradation process. Particulate matter in samples was firstly got rid of using $0.45 \mu \mathrm{m}$ filtering membrane, pretreated samples were added into a continuous flow system consisting of UF following the method of Zhao et al. (2006). And the molecular weight range for each fraction is listed in Table 2.

The quantity of dissolved organic carbon (DOC) corresponding to each size fraction of DOM after filtered with different pore-size UF membranes was calculated from DOC concentration and corresponding volume.

The ultrafilter is Amicon 8200 type ultrafiltration cup which was produced by the United States Millipore, having an effective volume of $180 \mathrm{~mL}$, effective film area of $28.7 \mathrm{~cm}^{2}$, maximum withstand pressure of $0.53 \mathrm{MPa}$, built-in magnetic stirring Pressure-driven high-purity nitrogen (Qiao et al. 2007).

\section{Analytical methods}

The $\mathrm{pH}$ value was measured by a $\mathrm{pH}$ meter (METTLER TOLEDO, FE20K). The content of $\mathrm{BOD}_{5}$ was measured by incubation method. The content of total nitrogen (TN) and total phosphorus (TP) were analyzed using alkaline potassium persulfate digestion-UV spectrophotometer and molybdenum blue spectrophotometric (Carranzo 2012). Dissolved organic carbon (DOC) in water samples were measured using UV-per-sulfate technique and infrared carbon dioxide analyzer (Phoenix 8000), and calibrated with potassium hydrogen phthalate.

\section{Authors' contributions}

$C Z, S R$, and $Y X$ designed the experiment. CQ and KR analyzed the data. CQ and $K R$ performed most of experiments in $P C R-D G G E$ section. CQ, KR, HX, and HB wrote the manuscript. All authors read and approved the final manuscript.

\section{Author details}

${ }^{1}$ Key Laboratory of Industrial Fermentation Microbiology, (Ministry of Education), Tianjin University of Science \& Technology, Tianjin 300457, People's Republic of China. ${ }^{2}$ Tianjin Academy of Environmental Sciences, Tianjin 300191, China. ${ }^{3}$ CNOOC Ener Tech Beijing Research Institute of Engineering \& Technology for Safety \& Environmental Protection, Tianjin 300457, China.

\section{Acknowledgements}

The authors duly acknowledge the Laboratory of Industrial Fermentation Microbiology, (Ministry of Education), Tianjin University of Science \& Technology, Tianjin Academy of Environmental Sciences, and CNOOC Ener Tech Beijing Research Institute of Engineering \& Technology for Safety \& Environmental Protection.

\section{Competing interests}

The authors declare that they have no competing interests.

\section{Availability of data and materials}

The authors have agreed to provide the data and materials for open access.

\section{Consent for publication}

The authors approved the consent for publishing the manuscript.

\section{Ethics approval and consent to participate}

All the authors have read and agreed the ethics for publishing the manuscript.

\section{Funding}

This work was financially supported by the National Natural Science Foundation of China (NSFC 51178311) and Natural Science Foundation of Tianjin (13ZCZDSF00700, 16JCTPJC46100).

\section{Publisher's Note}

Springer Nature remains neutral with regard to jurisdictional claims in published maps and institutional affiliations.

Received: 3 May 2017 Accepted: 30 June 2017

Published online: 10 July 2017

\section{References}

Al-Thukair AA, Abed RM, Mohamed L (2007) Microbial community of cyanobacteria mats in the intertidal zone of oil-polluted coast of Saudi Arabia. Mar Pollut Bull 54:173-179

Brito EMS, Guyoneaud R, Goñi-Urriza M, Ranchou-Peyruse A, Verbaere A, Crapez MAC, Wasserman JCA, Duran R (2006) Characterization of hydrocarbonoclastic bacterial communities from mangrove sediments in Guanabara Bay, Brazil. Res Microbial 157:752-762

Carranzo IV (2012) APHA, AWWA, WEF."Standard methods for examination of water and wastewater. Anales De Hidrología Médica 5(2)

Chang CN, Chao A, Lee FS (2000) Influence of molecular weight distribution of organic substances on the removal efficiency of DBPS in a conventional water treatment plant. Water Sci Technol 41:43-49

Chen BY, Chen SY, Lin MY, Chang JS (2006) Exploring bioaugmentation strategies for azo-dye decolorization using a mixed consortium of Pseudomonas luteola and Escherichia coli. Process Biochem 41:1574-1581

Chong NM, Pai SL, Chen CH (1997) Bioaugmentation of an activated sludge receiving $\mathrm{pH}$ shock loadings. Bioresour Technol 59:235-240

de Oliveira PL, Duarte MC, Ponezi AN, Durrant LR (2009) Use of Bacillus pumilus CBMAI 0008 and Paenibacillus sp. CBMAI 868 for colour removal from paper mill effluent. Braz J Microbiol 40:354-357

Devaraja TN, Yusoff FM, Shariff M (2002) Changes in bacterial populations and shrimp production in ponds treated with commercial microbial products. Aquaculture 206:245-256

El Fantroussi S, Agathos SN (2005) Is bioaugmentation a feasible strategy for pollutant removal and site remediation? Cur Opin Microbiol 8:268-275

Gopinath KP, Murugesan S, Abraham J, Muthukumar K (2009) Bacillus sp. mutant for improved biodegradation of Congo red: random mutagenesis approach. Bioresour Technol 100:6295-6300

Hamaguchi M, Kautto J, Vakkilainen E (2013) Effects of hemicellulose extraction on the kraft pulp mill operation and energy use: review and case study with lignin removal. Chem Eng Res Des 91:1284-1291

Head MA, Oleszkiewicz JA (2004) Bioaugmentation for nitrification at cold temperatures. Water Res 38:523-530 
Hernández M, Hernández-Coronado MJ, Ball AS, Arias ME (2001) Degradation of alkali-lignin residues from solid-state fermentation of wheat straw by streptomycetes. Biodegradation 12:219-223

Ikenaga M, Muraoka Y, Toyota K, Kimura M (2002) Community structure of the microbiota associated with nodal roots of rice plants along with the growth stages: estimation by PCR-RFLP analysis. Biol Fertil Soils 36:397-404

Kanaly RA, Harayama S (2000) Biodegradation of high-molecular-weight polycyclic aromatic hydrocarbons by bacteria. J Bacteriol 182(8):2059-2067

Kanaly RA, Bartha R, Watanabe K, Harayama S (2000) Rapid mineralization of benzo[a]pyrene by a microbial consortium growing on diesel fuel. Appl Environ Microbiol 66:4205

Kang S, Li X, Fan J, Chang J (2012) Solid fuel production by hydrothermal carbonization of black liquor. Bioresour Technol 110:715-718

Kumar L, Rathore V, Srivastava H (2001) 14C-[lignin]-lignocellulose biodegradation by bacteria isolated from polluted soil. Indian J Exp Biol 39:584-589

Liang T, Dong-Ping LU, Bang HU, Zhang WL, Jiang LL (2009) Project design of viscose fiber wastewater treatment plant. China water \& wastewater 25(18):58-61

Lin JH (2000) A new process for treatment of viscose fiber wastewater. China water \& wastewater 16(12):10-13

Miao LH, Li FR, Wen JL (2009) Biological treatment of high-pH and highconcentration black liquor of cotton pulp by an immediate aerobicanaerobic-aerobic process. Water Sci Technol 60:3275-3284

Muyzer G, Smalla K (1998) Application of denaturing gradient gel electrophoresis (DGGE) and temperature gradient gel electrophoresis (TGGE) in microbial ecology. Antonie Van Leeuwenhoek 73:127-141

Park D, Lee DS, Kim YM, Park JM (2008) Bioaugmentation of cyanide-degrading microorganisms in a full-scale cokes wastewater treatment facility. Bioresour Technol 99:2092

Qiao C, Wei Q, Wang D, Yang M, Wei Q (2007) Molecular weight distribution and removal characters of DOM in the typical source water in south of China. J Acta Sci Circum 27:195-200

Reberto L, Vazquez SC, Mac Cormack WP (2003) Effectiveness of the natural bacterial flora, biostimulation and bioaugmentation on the bioremediation of a hydrocarbon contaminated Antarctic soil. Int Biodeter Biodeg 52:115-125

Reineke W (1998) Development of hybrid strains for the mineralization of chloroaromatics by patchwork assembly. Annu Rev Microbiol 52:287-331
Saravanane R, Murthy DVS, Krishnaiah K (2001) Bioaugmentation and treatment of cephalexin drug-based pharmaceutical effluent in an upflow anaerobic fluidized bed system. Bioresour Technol 76:279-281

Schwarz W (2001) The cellulosome and cellulose degradation by anaerobic bacteria. Appl Microbiol Biotechnol 56:634-649

Singh S, Chandra R, Patel DK, Reddy MM, Rai V (2008) Investigation of the biotransformation of pentachlorophenol and pulp paper mill effluent decolorisation by the bacterial strains in a mixed culture. Bioresour Technol 99:5703-5709

Tuomela M, Vikman M, Hatakka A, Itävaara M (2000) Biodegradation of lignin in a compost environment: a review. Bioresour Technol 72:169-183

Vikman M, Karjomaa S, Kapanen A, Wallenius K, Itävaara M (2002) The influence of lignin content and temperature on the biodegradation of lignocellulose in composting conditions. Appl Microbiol Biotechnol 59:591-598

Wang JL, Xiang CQ, Li BW, Yi Q, Hegemann W (2002) Bioaugmentation as a too to enhance the removal of refractory compound in coke plant wastewater. Process Biochem 38:777-781

Wang X, Liu J, Huai-Bo GE, et al. (2013) Engineering of alkali recovery in cotton pulp black liquor treatment. China water \& wastewater 29(22):116-118

Watanabe K, Kodama Y, Harayama S (2001) Design and evaluation of PCR primers to amplify bacterial 165 ribosomal DNA fragments used for community fingerprinting. J Microbiol Methods 44(3):253-262

Wen Y, Zhao G, Zhou C, Cao A (2011) Research progress of microbial agents in ecological engineering. Acta Ecol Sin 31:6287-6294

Kang Q, Yi S (2005) Industrialization test of using acid-out +CASS+airfloatation way to treat plasm-scum wastewater. Tech Equip Environ Pollut Control 6:48-50

Widada J, Nojiri H, Omori T (2002) Recent developments in molecular techniques for identification and monitoring of xenobiotic-degrading bacteria and their catabolic genes in bioremediation. Appl Microbiol Biotechnol 60:45-59

Wilson DB (2004) Studies of Thermobifida fusca plant cell wall degrading enzymes. Chem Rec 4:72-82

Yu Z, Mohn W (2001) Bioaugmentation with resin-acid-degrading bacteria enhances resin acid removal in sequencing batch reactors treating pulp mill effluents. Water Res 35:883-890

Zhao ZY, Gua JD, Fan XJ (2006) Molecular size distribution of dissolved organic matter in water of the Pearl River and trihalomethane formation characteristics with chlorine and chlorine dioxide treatments. Hazard Mater 134:60

\section{Submit your manuscript to a SpringerOpen ${ }^{\odot}$ journal and benefit from:}

- Convenient online submission

- Rigorous peer review

- Open access: articles freely available online

- High visibility within the field

- Retaining the copyright to your article

Submit your next manuscript at $\boldsymbol{\Delta}$ springeropen.com 